antibody therapy with rituximab. Although rituximab has gained increasing use in the therapy of extranodal marginal zone lymphomas of MALT type, the curative potential of this modality is unknown. Further studies are necessary to advance our understanding of the role of antibiotic or antiviral therapy for this entity.

\section{Competing interests: None.}

Br J Ophthalmol 2008;92:446-448.

doi:10.1136/bjo.2007.134965

\section{REFERENCES}

1. Coupland SE, Damato B. Lymphomas involving the eye and the ocular adnexa. Curr Opin Ophthalmol 2006;17:523-31.

2. Isaacson $\mathbf{P}$, Wright $\mathrm{DH}$. Malignant lymphoma of mucosa-associated lymphoid tissue. A distinctive type of B-cell lymphoma. Cancer 1983;52:1410-6.

3. Suarez $\mathbf{F}$, Lortholary 0 , Hermine 0 , et al. Infectionassociated lymphomas derived from marginal zone B cells: a model of antigen-driven lymphoproliferation. Blood 2006:107:3034-44.

4. Moslehi R, Devesa SS, Schairer C, et al. Rapidly increasing incidence of ocular non-Hodgkin lymphoma. J Natl Cancer Inst 2006;98:936-9.

5. Roggero E, Zucca E, Mainetti C, et al. Eradication of Borrelia burgdorferi infection in primary marginal zone B-cell lymphoma of the skin. Hum Pathol 2000:31:263-8.

6. Lecuit M, Abachin E, Martin A, et al. Immunoproliferative small intestinal disease associated with Campylobacter jejuni. N Engl J Med 2004;350:239-48.

7. Bertoni F, Zucca E. State-of-the-art therapeutics: marginal-zone lymphoma. J Clin Oncol 2005;23:6415-20.
8. Arima N, Tsudo M. Extragastric mucosa-associated lymphoid tissue lymphoma showing the regression by Helicobacter pylori eradication therapy. Br J Haematol 2003:120:790-2.

9. Alkan S, Karcher DS, Newman MA, et al. Regression of salivary gland MALT Iymphoma after treatment for Helicobacter pylori. Lancet 1996;348:268-9.

10. Ferreri AJ, Ponzoni M, Viale E, et al. Association between Helicobacter pylori infection and MALT-type Iymphoma of the ocular adnexa: clinical and therapeutic implications. Hematol Oncol 2006;24:33-7.

11. Chan CC, Smith JA, Shen DF, et al. Helicobacter pylori (H. pylori) molecular signature in conjunctival mucosa-associated lymphoid tissue (MALT) lymphoma. Histol Histopathol 2004:19:1219-26.

12. Sjo NC, Foegh P, Juhl BR, et al. Role of Helicobacter pylori in conjunctival mucosa-associated lymphoid tissue lymphoma. Ophthalmology 2007:114:182-6.

13. Lee S-B, Yang J-W, Kim C-S. The association between conjuctival MALT Iymphoma and Helicobacter pylori. Br J Ophthalmol 2008;92:534-6.

14. Chanudet E, Zhou Y, Bacon CM, et al. Chlamydia psittaci is variably associated with ocular adnexal MALT lymphoma in different geographical regions. J Pathol 2006;209:344-51.

15. Ferreri AJ, Guidoboni M, Ponzoni M et al. Evidence for an association between Chlamydia psittaci and ocular adnexal lymphomas. J Natl Cancer Inst 2004;96:586-94.

16. Daibata M, Nemoto $Y$, Togitani $K$, et al. Absence of Chlamydia psittaci in ocular adnexal lymphoma from Japanese patients. Br J Haematol 2006;132:651-2.

17. de Cremoux $\mathbf{P}$, Subtil A, Ferreri AJ, et al. Re: Evidence for an association between Chlamydia psittaci and ocular adnexal lymphomas. J Natl Cancer Inst 2006;98:365-6.

18. Yoo C, Ryu MH, Huh J, et al. Chlamydia psittaci infection and clinicopathologic analysis of ocular adnexal lymphomas in Korea. Am J Hematol 2007.

19. Rosado MF, Byrne GE Jr, Ding F, et al. Ocular adnexal lymphoma: a clinicopathologic study of a large cohort of patients with no evidence for an association with Chlamydia psittaci. Blood 2006;107:467-72.
20. Vargas RL, Fallone E, Felgar RE, et al. Is there an association between ocular adnexal lymphoma and infection with Chlamydia psittaci? The University of Rochester experience. Leuk Res 2006;30:547-51.

21. Zhang GS, Winter JN, Variakojis D, et al. Lack of an association between Chlamydia psittaci and ocular adnexal lymphoma. Leuk Lymphoma 2007:48:577-83.

22. Mulder MM, Heddema ER, Pannekoek Y, et al. No evidence for an association of ocular adnexal lymphoma with Chlamydia psittaci in a cohort of patients from the Netherlands. Leuk Res 2006:30:1305-7.

23. Ferreri AJ, Ponzoni M, Guidoboni M, et al. Bacteriaeradicating therapy with doxycycline in ocular adnexal MALT Iymphoma: a multicenter prospective trial. J Natl Cancer Inst 2006;98:1375-82.

24. Husain A, Roberts D, Pro B, et al. Meta-analyses of the association between Chlamydia psittaci and ocular adnexal lymphoma and the response of ocular adnexal lymphoma to antibiotics. Cancer 2007;110:809-815.

25. Abramson DH, Rollins I, Coleman M. Periocular mucosa-associated lymphoid/low grade lymphomas: treatment with antibiotics. Am J Ophthalmol 2005;140:729-30.

26. Ferreri AJ, Ponzoni M, Guidoboni $M$, et al. Regression of ocular adnexal lymphoma after Chlamydia psittaci-eradicating antibiotic therapy. J Clin Oncol 2005;23:5067-73.

27. Grunberger B, Hauff W, Lukas J, et al. 'Blind' antibiotic treatment targeting Chlamydia is not effective in patients with MALT lymphoma of the ocular adnexa. Ann Oncol 2006:17:484-7.

28. Liu H, Ruskon-Fourmestraux A, Lavergne-Slove A, et al. Resistance of $t(11 ; 18)$ positive gastric mucosaassociated lymphoid tissue lymphoma to Helicobacte pylori eradication therapy. Lancet 2001;357:39-40.

29. IELSG. A clinico-pathological phase II study with translational elements to investigate the possible infective causes of MALT lymphoma of the ocular adnexa with particular reference to Chlamydia species and the effects of treatment with tetracycline. Protocol available via the IELSG Trial Coordination Centre. http://www.ielsg.org/trialsonfr.html (accessed 17 Dec 2007)

\title{
Inflammation in the pathogenesis of age-related macular degeneration
}

\author{
Atsuhiro Kanda, ${ }^{1}$ Goncalo Abecasis, ${ }^{2}$ \\ Anand Swaroop ${ }^{1,3,4}$
}

Degenerative diseases of the retina can have a devastating impact on quality of life and constitute a major cause of

\footnotetext{
${ }^{1}$ Department of Ophthalmology and Visual Sciences, University of Michigan, Ann Arbor, MI, USA;

${ }^{2}$ Department of Biostatistics, University of Michigan, Ann Arbor, MI, USA; ${ }^{3}$ Department of Human Genetics, University of Michigan, Ann Arbor, MI, USA;

${ }^{4}$ Neurobiology, Neurodegeneration \& Repair Laboratory, National Eye Institute, National Institutes of Health, Bethesda, MD, USA

Correspondence to: Dr A Swaroop, Neurobiology, Neurodegeneration \& Repair Laboratory (N-NRL), National Eye Institute, National Institutes of Health, Bldg 10/10B11, MSC1864, Bethesda, MD 20892, USA: swaroopa@nei.nih.gov
}

untreatable blindness in developed countries. Age-related macular degeneration (AMD) stands out among these, as it leads to visual dysfunction in a significant fraction of the elderly population worldwide. AMD primarily affects the macular region of the retina; early signs of the disease include the appearance of soft drusen and regions of altered pigmentation in the retina, whereas advanced stages exhibit choroidal neovascularisation or atrophy of photoreceptors and the retinal pigment epithelium (RPE). ${ }^{1-3}$ Diverse cellular processes have been implicated in $\mathrm{AMD}$ pathogenesis, including inflammation, oxidative stress, altered cholesterol metabolism and/or impaired function of the RPE. ${ }^{3-6}$ It is widely believed that manifestation of distinct disease characteristics in AMD is the result of a complex interplay among genetic and environmental factors. ${ }^{78}$ Although the casual pathways underlying $\mathrm{AMD}$ are not fully understood, this multifactorial neurodegenerative disease has received considerable attention in the last few years, as rapid advances in genetics and genomics have provided insights into the underlying pathophysiology, potentially opening avenues for new treatment paradigms.

On the basis of the presence of immune response proteins in drusen of postmortem AMD retinas, Hageman and colleagues were the first to suggest a link between inflammation and AMD. ${ }^{10}$ However, direct evidence for the role of immunoregulatory molecules came from genetic studies that identified strong association of AMD with variants in complement factor $\mathrm{H}(\mathrm{CFH}) .{ }^{811-14}$ This association is now firmly established 


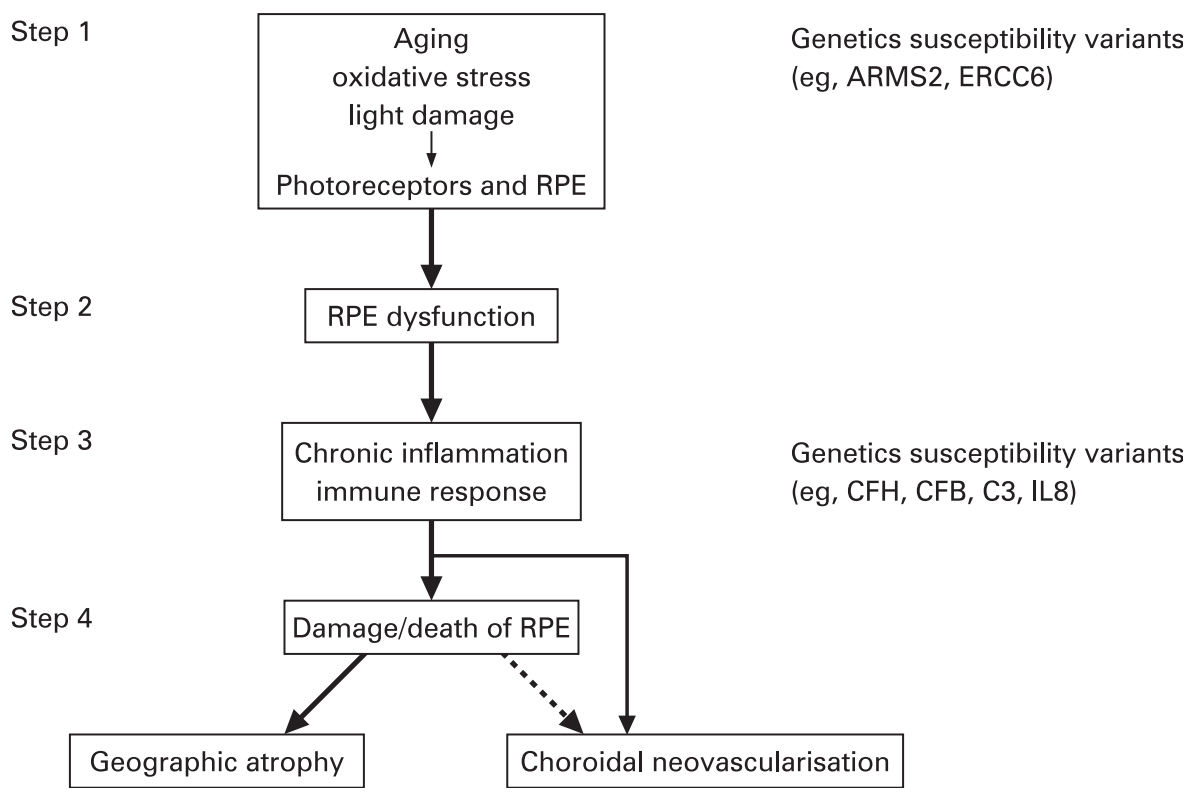

Figure 1 Proposed steps in the pathogenesis of age-related macular degeneration (based on recent genetic studies and Zarbin ${ }^{3}$ and Zonoso et $\left.a l^{10}\right)$. RPE, retinal pigment epithelium.

through replications in numerous independent cohorts. ${ }^{15-17}$ The strong link between $\mathrm{AMD}$ and $\mathrm{CFH}$ polymorphisms provided an impetus for the careful assessment of genetic variation in other complement pathway genes. AMD susceptibility variants have now been identified in complement component 2 (CC2) and complement factor $\mathrm{B}(\mathrm{CFB})^{18} 19$ and complement component 3 (C3). ${ }^{2021}$ Association with AMD has also been suggested in chemokine (C-X3-C motif) receptor 1 (CX3CR1), Toll-like receptor 4 (TLR4) and major histocompatibility complex class I (HLA) genes. ${ }^{22-24}$

In this issue, Goverdhan and colleagues $^{25}$ report their study of genetic variants in four cytokine genes (including the pro-inflammatory interleukin (IL)1b, IL6, IL8 and anti-inflammatory IL10) (see page 537). They suggest that the $-251 \mathrm{~A}$ allele (rs4073) of the IL8 promoter is more prevalent in AMD cases than controls $(p=0.037)$. As with all initial reports of association, this signal must be confirmed in larger samples before a definite link between IL8 polymorphism and $\mathrm{AMD}$ can be confidently identified. Nevertheless, this possibility is mechanistically very interesting. IL8, a potent chemo-attractant and activator of neutrophils, is primarily involved in the initiation and amplification of acute inflammatory reactions and in chronic inflammatory processes. It can be produced by a variety of cell types, including macrophages, neutrophils and endothelial cells, in response to inflammatory stimuli. ${ }^{26}$ Tentative associations between the rs4073 single-nucleotide polymorphism and inflammatory, gastric and neurodegenerative diseases have previously been reported, and this variant appears to enhance IL8 production in vivo. ${ }^{27}$ In the context of AMD pathogenesis, the response to reactive oxygen species in photoreceptor outer segments or inflammatory injury can lead to increased monocyte chemotactic protein-1 from RPE cells ${ }^{28}$ (S Miller, personal communication). It is tempting to speculate that even a slight increase in IL8 expression in individuals carrying the rs4073 variant may exacerbate RPE damage and favour progression towards advanced AMD.

Aging-associated changes, together with photo-oxidative stress, in photoreceptors and RPE appear to be the initial triggers of maculopathy, and the subsequent cellular damage is amplified in time by inflammation/immune response (fig 1 ). Susceptibility variants in genes that modulate stress and inflammatory responses may therefore influence the clinical presentation of AMD. Disease onset and severity are also likely to be affected by environmental factors (such as smoking). Variants in and around CFH at chromosome 1q31 and in ARMS2/LOC387715 at chromosome $10 \mathrm{q} 26$ are so far the strongest AMD susceptibility alleles. ${ }^{811-1629}$ $\mathrm{CFH}$ and neighbouring genes regulate complement pathway by promoting the decay of C3 convertase and by acting as a cofactor for factor I-medicated proteolysis of C3b. Experiments are underway to characterise how genetic polymorphism expression and secretion of IL8 and in CFH leads to increased susceptibility to AMD. Furthermore, the concentrations of C-reactive protein, a systemic marker of subclinical inflammation, are increased in eyes that are homozygous for one of the $\mathrm{CFH}$-associated susceptibility variants, Y402H. ${ }^{11}$ In addition, IL10 has been shown to regulate macrophage function and alter ocular angiogenesis in older mice, indicating an additional link of inflammatory response to aging and disease process. ${ }^{30}$

Taken together, current evidence suggests that anomalies in inflammatory immune responses may trigger progression of maculopathy towards advanced clinical features (eg, choroidal neovascularisation or geographic atrophy; fig 1). This link and other processes underlying AMD will continue to become clearer as genetic and biochemical studies yield novel insights. We expect that more clues will be forthcoming in the next year, permitting us to better understand the clinical aspects of this debilitating blinding disease.

Acknowledgements: We apologise to colleagues whose papers have not been cited because of limited space. We thank John Heckenlively, Kari Branham and Mohammad Othman for discussions, Sheldon Miller for sharing unpublished observations, and Sarah Sohraby for comments on the manuscript. This work was supported by National Institutes of Health (EY016862, and NEI intramural funds), The Foundation Fighting Blindness, Research to Prevent Blindness, Thompson Foundation and the Sramek Foundation. AK is supported in part by the Suntory Institute for Bioorganic Research (Osaka, Japan).

Competing interests: None declared

Accepted 6 December 2007

Br J Ophthalmol 2008;92:448-450.

doi:10.1136/bjo.2007.131581

\section{REFERENCES}

1. Bird AC, Bressler NM, Bressler SB, et al. An international classification and grading system for age-related maculopathy and age-related macular degeneration. The International ARM Epidemiological Study Group. Surv Ophthalmol 1995;39:367-74.

2. de Jong PT. Age-related macular degeneration. N Engl J Med 2006;355:1474-85.

3. Zarbin MA. Current concepts in the pathogenesis of age-related macular degeneration. Arch Ophthalmol 2004;122:598-614.

4. Beatty S, Koh H, Phil M, et al. The role of oxidative stress in the pathogenesis of age-related macular degeneration. Surv Ophthalmol 2000;45:115-34.

5. Abeywickrama C, Matsuda $H$, Jockusch $S$, et al. Immunochemical recognition of $A 2 E$, a pigment in the lipofuscin of retinal pigment epithelial cells. Proc Natl Acad Sci USA 2007;104:14610-15.

6. Lakkaraju A, Finnemann SC, Rodriguez-Boulan E. The lipofuscin fluorophore A2E perturbs cholesterol metabolism in retinal pigment epithelial cells. Proc Natl Acad Sci USA 2007:104:11026-31.

7. Evans JR. Risk factors for age-related macular degeneration. Prog Retin Eye Res 2001;20:227-53.

8. Swaroop A, Branham KEH, Chen W, et al. Genetic susceptibility to age-related macular degeneration: a paradigm for dissecting complex disease traits. Hum Mol Genet 2007;16 Spec No 2:R174-82. 
9. Hageman GS, Luthert PJ, Victor Chong NH, et al. An integrated hypothesis that considers drusen as biomarkers of immune-mediated processes at the RPE-Bruch's membrane interface in aging and agerelated macular degeneration. Prog Retin Eye Res 2001;20:705-32.

10. Donoso LA, Kim D, Frost A, et al. The role of inflammation in the pathogenesis of age-related macular degeneration. Surv Ophthalmol

2006;51:137-52.

11. Klein RJ, Zeiss C, Chew EY, et al. Complement factor $\mathrm{H}$ polymorphism in age-related macular degeneration. Science 2005:308:385-9.

12. Edwards A0, Ritter R 3rd, Abel KJ, et al. Complement factor $\mathrm{H}$ polymorphism and age-related macular degeneration. Science 2005;308:421-4.

13. Hageman GS, Anderson DH, Johnson LV, et al. A common haplotype in the complement regulatory gene factor $\mathrm{H}$ (HF1/CFH) predisposes individuals to age-related macular degeneration. Proc Natl Acad Sci USA 2005;102:7227-32.

14. Haines JL, Hauser MA, Schmidt S, et al. Complement factor $\mathrm{H}$ variant increases the risk of age-related macular degeneration. Science 2005;308:419-21.

15. Li M, Atmaca-Sonmez P, Othman M, et al. $\mathrm{CFH}$ haplotypes without the $\mathrm{Y} 402 \mathrm{H}$ coding variant show strong association with susceptibility to agerelated macular degeneration. Nat Genet 2006;38:1049-54.
16. Maller J, George S, Purcell S, et al. Common variation in three genes, including a noncoding variant in $\mathrm{CFH}$, strongly influences risk of age-related macular degeneration. Nat Genet 2006;38:1055-9.

17. Johnson PT, Betts KE, Radeke MJ, et al. Individuals homozygous for the age-related macular degeneration risk-conferring variant of complement factor $\mathrm{H}$ have elevated levels of CRP in the choroid. Proc Natl Acad Sci USA 2006;103:17456-61.

18. Gold B, Merriam JE, Zernant J, et al. Variation in factor B (BF) and complement component 2 (C2) genes is associated with age-related macular degeneration. Nat Genet 2006;38:458-62.

19. Spencer KL, Hauser MA, Olson LM, et al. Protective effect of complement factor B and complement component 2 variants in age-related macular degeneration. Hum Mol Genet 2007;16:1986-92.

20. Maller JB, Fagerness JA, Reynolds RC, et al. Variation in complement factor 3 is associated with risk of age-related macular degeneration. Nat Genet 2007;39:1200-1.

21. Yates JR, Sepp T, Matharu BK, et al. Complement C3 variant and the risk of age-related macular degeneration. N Engl J Med 2007;357:533-61.

22. Tuo J, Smith BC, Bojanowski CM, et al. The involvement of sequence variation and expression of CX3CR1 in the pathogenesis of age-related macular degeneration. FASEB J 2004;18:1297-9.

23. Zareparsi S, Buraczynska M, Branham KE, et al. Tolllike receptor 4 variant D299G is associated with susceptibility to age-related macular degeneration. Hum Mol Genet 2005:14:1449-55.

24. Goverdhan SV, Howell MW, Mullins RF, et al. Association of HLA class I and class II polymorphisms with age-related macular degeneration. Invest Ophthalmol Vis Sci 2005;46:1726-34.

25. Goverdhan SV, Ennis S, Hannan SR, et al. Interleukin 8 promoter polymorphism $-251 \mathrm{~A} / \mathrm{T}$ is a risk factor for age related macular degeneration. $\mathrm{Br} J$ Ophthalmol 2008;92:

26. Taub DD, Oppenheim JJ. Chemokines, inflammation and the immune system. Ther Immunol 1994;1:229 46.

27. Hull J, Thomson A, Kwiatkowski D. Association of respiratory syncytial virus bronchiolitis with the interleukin 8 gene region in UK families. Thorax 2000;55:1023-7.

28. Higgins GT, Wang JH, Dockery $\mathrm{P}$, et al. Induction of angiogenic cytokine expression in cultured RPE by ingestion of oxidized photoreceptor outer segments. Invest Ophthalmol Vis Sci 2003:44:1775-82.

29. Kanda A, Chen W, Othman M, et al. A variant of mitochondrial protein LOC387715/ARMS2, not HTRA1, is strongly associated with age-related macular degeneration. Proc Natl Acad Sci USA 2007:104:16227-32

30. Kelly J, Khan AA, Yin J, et al. Senescence regulates macrophage activation and angiogenic fate at sites of tissue injury in mice. J Clin Invest 2007; 117:3421-6. 